\title{
Opioid switch from low dose of oral oxycodone to transdermal fentanyl matrix patch for patients with stable thoracic malignancy-related pain
}

Seigo Minami ${ }^{1}$, Takashi Kijima ${ }^{2 *}$, Takeshi Nakatani ${ }^{1}$, Suguru Yamamoto ${ }^{1}$, Yoshitaka Ogata ${ }^{1}$, Haruhiko Hirata ${ }^{2}$, Takayuki Shiroyama', ${ }^{1}$ Taro Koba ${ }^{1}$ and Kiyoshi Komuta ${ }^{1}$

\begin{abstract}
Background: The effectiveness and safety of switch from oral oxycodone to fentanyl patch is little known. Here, we investigated if early phase opioid switch from low dose of oral oxycodone to transdermal fentanyl matrix patch provided any benefits for patients with thoracic malignancy and stable cancer-related pain.

Methods: This open-label two-centered prospective study enrolled patients with thoracic malignancy suffering persistent malignancy-related pain with numeric rating scale of pain intensity $\leq 3$ which had been controlled by oral oxycodone $\leq 20 \mathrm{mg} / \mathrm{day}$. Eligible patients switched from oral oxycodone to $12.5 \mu \mathrm{g} / \mathrm{h}$ of transdermal fentanyl matrix patch. The dose was allowed to be titrated upwards every 3 day by $25-50 \%$, except for the first increase from $12.5 \mu \mathrm{g} / \mathrm{hr}$ to $25 \mu \mathrm{g} / \mathrm{hr}$,until achieving adequate pain control. The data on patients' global assessment scores measured on a five-step scale, an 11-point numeric rating scale of pain intensity, the severity of adverse effects using a four-point categorical rating scale, and the Epworth sleepiness scale questionnaire were collected for 15 days.

Results: Forty-nine eligible patients were analyzed. Overall patients' satisfaction score significantly improved from day 1 $(2.7 \pm 0.9)$ to day $15(2.3 \pm 0.9)(p<0.05)$, and $90 \%$ and $78 \%$ of patients remained to receive the minimum dose of fentanyl patch on day 8 and 15 from the opioid switch. There was a significant difference in sleepiness throughout the study period, though no difference was detected in pain intensity and other adverse effects.
\end{abstract}

Conclusion: Transdermal fentanyl matrix patch is an alternative analgesic option for a stable cancer pain in patients with thoracic malignancies.

Keywords: Transdermal fentanyl matrix patch, Oxycodone, Opioid switch, Pain, Thoracic malignancy

\section{Background}

Cancer-related pain is the most important concern in patients suffering cancer. More than $80 \%$ of patients with advanced disease experience cancer-related pain caused largely by direct tumor invasion [1]. Cancer-related pain often disturbs activities of daily living and deteriorates quality-of-life [2].

Opioids are the mainstay of analgesic therapy for moderate to severe cancer-related pain, according to the current guidelines [1,3]. Oxycodone, a semi-synthetic opioid

\footnotetext{
* Correspondence: tkijima@imed3.med.osaka-u.ac.jp

${ }^{2}$ Department of Respiratory Medicine, Allergy and Rheumatic Diseases, Osaka University Graduate School of Medicine, 2-2 Yamada-oka, Suita, Osaka 565-0871, Japan

Full list of author information is available at the end of the article
}

analgesic, has become a cornerstone in symptom management of cancer-related pain [4-6]. Controlled-release of oxycodone is often administered as the first-line strong opioid, typically at an initial dose of 5-10 mg every 12 hours in opioid-naïve patients, when non-steroidal anti-inflammatory drugs (NSAIDs) and weak opioids are ineffective.

On the other hand, the high lipid solubility and low molecular weight of fentanyl is suitable for transdermal administration. In 2002, a transdermal therapeutic system (TTS) for fentanyl incorporating a gel reservoir technology was first marketed as the Durotep Patch (JanssenPharma, Japan). In 2008, a transdermal fentanyl matrix patch (Durotep ${ }^{\circ}$ MT patch, Janssen-Pharma, Japan), a new TTS that contains fentanyl dissolved in the adhesion layer, 
has become available in Japan. The smallest size of the matrix patch, with fentanyl release rates of $12.5 \mu \mathrm{g} / \mathrm{h}$, makes it possible to switch from lower dose of other opioid and then gradually titrate to the effectual dose [7]. Fentanyl may has not only a powerful analgesic effect, but advantage of less frequent and milder adverse effects such as nausea, vomiting, constipation and sleepiness [8-12]. Compared with oral morphine, fentanyl may have advantage especially in constipation, but there are concerns over methodological problems of constipation assessment. In a crossover trial, constipation was less frequent under transdermal fentanyl than under oral morphine, though the assessment methods of constipation remained unclear [9]. In another comparison study, the use of laxatives given by nurses was investigated instead of assessment of constipation and shown to be less frequent in fentanyl [12]. Two meta-analyses $[13,14]$ and a systematic review [15] also indicated a significant reduction in constipation for fentanyl patch compared with oral morphine. In contrast, another prospective comparison study showed that transdermal opioids of fentanyl and buprenorphine had no benefit over controlled release oral hydromorphone in gastrointestinal symptoms including constipation [16]. However, the evidence on an advantage of fentanyl patch over oral opioids is low level, because the trials regarding fentanyl patch were limited, not blinded and of low methodological quality [3].

Opioid switch is a therapeutic maneuver aiming at improvement of analgesic response and reduction of adverse effects [17]. The maneuver includes change to different medication using the same administration route, alteration of administration route maintaining the current medication, or both. Fentanyl patch is the most favorable candidate of opioid switch from oral opioids because of less adverse effects and easier administration route $[9,10,18,19]$. Switch from oral morphine to transdermal fentanyl patch was shown as an effective and safe method $[9,10]$, though the drop-out rate with fentanyl was higher than that with morphine in a crossover trial [9]. In contrast, little is known about the benefits of switch from oral oxycodone to fentanyl patch.

In this study, we investigated if early phase opioid switch from low dose of oral oxycodone to transdermal fentanyl matrix patch provided any benefits for patients with stable cancer-related pain.

\section{Methods}

\section{Patient eligibility}

Patients with thoracic malignancy-related pain were recruited in Osaka Police Hospital and Osaka University Hospital. The patients who met all the following criteria were eligible; 1) confirmed diagnosis of thoracic malignancy, 2) age $\geq 20$ years, 3) persistent malignancy-related pain refractory to non-steroidal anti-inflammatory drugs
(NSAIDs) or acetaminophen, 4) numeric rating scale (NRS) for pain $\leq 3$ for at least two consecutive days by low dose (20 mg/day or less) of oral oxycodone (Oxycontine ${ }^{\circ}$, Shionogi-Pharma, Japan). Exclusion criteria were as follows; 1 ) prior history of allergy or hypersensitivity to opioids, 2) prior history of opioid abuse, 3) clinically significant cardiac, renal or hepatic insufficiency, 4) increased intracranial pressure or impaired cognitive function, 5) active and extensive skin disease precluding application of the transdermal delivery system, 6) persistent fever of 40 degrees Celsius or over, 7) pregnancy, lactation and suspicion of being pregnant, 8) prior use of any opioid-antagonists within 2 days before switching to fentanyl patch. Concomitant treatments such as chemotherapy and radiotherapy at the enrollment were accruable.

\section{Study design and treatment}

All patients recorded the following data daily for 15 days of fentanyl patch treatment; 1) pain intensity using an 11-point NRS (scales 0-10), 2) the severity of adverse effects (e.g., nausea, vomiting, constipation and sleepiness) using a four-point categorical rating scale (none $=0$, not hard $=1$, hard but endurable $=2$ and unendurably hard $=$ $3)$, 3) the number of defecation per day, 4) the Epworth sleepiness scale (ESS) questionnaire except for the question on sleepiness during driving a car because strong opioids are not permitted for drivers in Japan, 5) the frequencies of immediate-release oxycodone (Oxinorm ${ }^{\circ}$, Shionogi-Pharma, Japan) medications per day. Time of recording diary was arbitrary. The diaries were collected after 15 days of fentanyl patch treatment. The patients' global assessment scores were also rated using a fivestep scale (very satisfied $=$ category 1 , satisfied $=2$, neither satisfied nor dissatisfied $=3$, dissatisfied $=4$ and very dissatisfied $=5$ ) [20] on days 1,8 and 15 . Oral oxycodone was switched to $12.5 \mu \mathrm{g} / \mathrm{h}$ of transdermal fentanyl matrix patch. In the morning on the switch day (day 1$)$, a fentanyl patch $(2.1 \mathrm{mg} / 3$ days) was applied at the same time of the oral intake of the last controlledrelease oxycodone dose. Rescue immediate-release oxycodone dose to relieve the breakthrough pain was adjusted according to the dose of transdermal fentanyl patch. The dose of transdermal fentanyl patch was allowed to be titrated upwards every 3 days by $25-50 \%$, except for the first increase from $2.1 \mathrm{mg} /$ patch $(12.5 \mu \mathrm{g} / \mathrm{hr})$ to $4.2 \mathrm{mg} /$ patch $(25 \mu \mathrm{g} / \mathrm{hr})$, until patients could achieve adequate pain control. Transdermal fentanyl patch treatment was continued for 15 days ( 5 replacements). Neither addition nor dose change of other supplementary analgesics was permitted during the study.

The primary endpoint in this study was patients' global assessment scores. Secondary endpoints were pain intensity, adverse effects and use of rescue oxycodone. 
The study protocol was approved by the Institutional Review Board of Osaka University Hospital and the Osaka Police Hospital ethics committee, adhered to the principles outlined in the Guideline for Good Clinical Practice (January 1997) and Declaration of Helsinki (1996), and registered as UMIN000011067. Written informed consent was obtained from all patients before commencement of the study.

\section{Statistical analysis}

We expected that $85 \%$ of patients would give the global assessment scores 1 to 3 , on the basis of the data from a previous Japanese clinical trial of Durotep ${ }^{\oplus} \mathrm{MT}$ patch reporting that the patients' satisfaction was $89.4 \%$ [20]. The estimated number of patients for analysis was 49 with a confidence interval of $95 \%$ and $\beta$-error of $10 \%$. Given the possibility of deviation from assessment, 60 patients were necessary.

Listwise deletion was adopted in cases in which we missed data at opioid switch (day 1). Patients who dropped out without completion of 15-day patch treatment were also deleted from analysis. Missing data at days 8 and 15 from opioid switch were handled using last observation carried forward (LOCF) imputation technique.

The data for normally distributed continuous variables, discrete variables, and categorical variables are expressed as the mean \pm standard deviation (SD), median with range, and frequency. Friedman test, with a post-hoc Steel test, was used to compare longitudinal changes in numeric and categorical rating scales and ESS questionnaire scores. Significance was set at $p<0.05$. All statistical analyses were performed using Statcel statistical package (Statcel3; OMS Inc., Tokorozawa, Japan).

\section{Results}

Although enrollment to this study was planned to complete within 2 years, only 50 patients were accrued for 4 years, despite of 2-year extension of the study period. Therefore, this study was terminated in December 2012 because of delayed accrual. The final accrual did not reach 60 patients, the preplanned sample size.

From February 2009 to December 2012, a total of 50 eligible patients switched opioids. Almost all patients completed 15 days of fentanyl matrix patch treatment except one patient who suddenly died of cancer progression on the 13rd day from opioid switch. During the study period, $51 \%$ and $24 \%$ of patients concomitantly received chemotherapy and radiotherapy, respectively. The baseline characteristics are shown in Table 1.

Overall patients' satisfaction was significantly different throughout the study period (Friedman test; $p<0.01$ ). The proportion of patients in category 1 or 2 ('very satisfied' or 'satisfied') for the patient's global assessment
Table 1 Patients' characteristics $(\mathrm{N}=49)$

\begin{tabular}{|c|c|}
\hline \multicolumn{2}{|l|}{ Sex } \\
\hline Male/Female & $43 / 6$ \\
\hline Age (years-old) & $69.0 \pm 6.9$ \\
\hline Body mass index $\left(\mathrm{kg} / \mathrm{m}^{2}\right)$ & $20.4 \pm 4.9$ \\
\hline \multicolumn{2}{|l|}{ Cancer (Histology) } \\
\hline Lung Cancer (Ad/SQ/SCLC/Others) & $48(26 / 14 / 4 / 4)$ \\
\hline Mesothelioma & 1 \\
\hline \multicolumn{2}{|l|}{ Stage } \\
\hline$\|B /\| A / \| B / V^{a}$ & $1 / 4 / 7 / 37^{\mathrm{a}}$ \\
\hline \multicolumn{2}{|l|}{ ECOG PS } \\
\hline $0-1 / 2 / 3 / 4$ & $28 / 13 / 5 / 3$ \\
\hline \multicolumn{2}{|l|}{ Pain location ${ }^{\mathrm{b}}$} \\
\hline \multicolumn{2}{|c|}{$\begin{array}{l}\text { Neck-shoulder/Upper limb/Chest/Hypochondrium/ } \\
\text { Lower back/Glutaeus to thigh }\end{array}$} \\
\hline & $4 / 2 / 32 / 1 / 7 / 5$ \\
\hline \multicolumn{2}{|l|}{ Pain causes ${ }^{b}$} \\
\hline \multicolumn{2}{|c|}{ Distant metastasis (bone)/Invasion/Pleural dissemination } \\
\hline & $22(17) / 18 / 11$ \\
\hline \multicolumn{2}{|l|}{ Duration of cancer pain (months) } \\
\hline mean $\pm S D$ & $4.3 \pm 4.4$ \\
\hline median (range) & $2(0.27-18)$ \\
\hline \multicolumn{2}{|c|}{ Duration of controlled-release oxycodone administration (months) } \\
\hline mean $\pm S D$ & $2.0 \pm 4.3$ \\
\hline median (range) & $0.6(0.1-19.7)$ \\
\hline \multicolumn{2}{|l|}{ Fentanyl patch treatment site } \\
\hline \multicolumn{2}{|l|}{ day 1} \\
\hline Hospitalized/Outpatient & $40 / 9$ \\
\hline \multicolumn{2}{|l|}{ day 8} \\
\hline Hospitalized/Outpatient & $32 / 17$ \\
\hline \multicolumn{2}{|l|}{ day 15} \\
\hline Hospitalized/Outpatient & $22 / 27$ \\
\hline \multicolumn{2}{|l|}{ Concomitant systemic chemotherapy } \\
\hline Yes/No & $25 / 24$ \\
\hline \multicolumn{2}{|l|}{ Concomitant radiotherapy } \\
\hline Yes/No & $12 / 37$ \\
\hline
\end{tabular}

Ad, Adenocarcinoma; SQ, Squamous cell carcinoma; SCLC, Small cell lung carcinoma; ECOG PS, European Clinical Oncology Group Performance status; $\mathrm{SD}$, standard deviation.

ancluding a case with malignant mesothelioma in c-stage IV.

bThere were two overlapping.

score increased from $43 \%$ on day 1 to $63 \%$ on day 8 and $61 \%$ on day 15 , while the proportion of patients in category 1-3 ('very satisfied', 'satisfied' or 'neither satisfied nor dissatisfied') hardly changed from $87 \%$ on day 1 to 91\% on day 15 (Table 2).

Oxycodone doses on day 1 differed from 10 to $20 \mathrm{mg} /$ day. Fentanyl matrix patch dose remained $12.5 \mu \mathrm{g} / \mathrm{h}$ in 44 patients $(90 \%)$ on day 8 and 38 patients $(78 \%)$ on day 
Table 2 Change of patients' global assessment scores $\left(\mathrm{N}=46^{\mathrm{a}}\right)$

\begin{tabular}{lccc}
\hline & Day 1 & Day 8 & Day 15 \\
\hline mean \pm SD & $2.7 \pm 0.9$ & $2.4 \pm 0.9$ & $2.3 \pm 0.9$ \\
median (range) & $3(1-5)$ & $2(1-5)$ & $2(1-5)$ \\
vs. day 1 & & n.s. & n.s. \\
Patients' distribution (N) & 2 & & \\
1. Very satisfied & 18 & 24 & 9 \\
2. Satisfied & 20 & 12 & 19 \\
3. Neither & 4 & 4 & 14 \\
4. Dissatisfied & 2 & 1 & 1 \\
5. Very dissatisfied & & 5 & \\
\hline
\end{tabular}

${ }^{a}$ Three patients were excluded from analysis because of missing data throughout all the three observation points.

${ }^{b}$ Post-hoc nonparametric multiple comparison analysis was performed using Steel method after significant difference in assessment scores across multiple points was detected by Freidman test $(p<0.01)$.

n.s.; not significant $(p>0.05)$.

SD; standard deviation.

15 , and increased up to more than $25 \mu \mathrm{g} / \mathrm{h}$ in 10 patients (20\%) during the study period (Table 3 ). Six, eight and six patients felt pain with NRS $\geq 4$ at day 1, 8 and 15, respectively. Among them, one, two and two patients were under outpatient care at day 1,8 and 15 , respectively. There was no significant difference between 3 measurement days in pain intensity, rescue dose of oxycodone and adverse effects except sleepiness (Friedman test, $p=0.01$ ) (Tables 4 and 5 and Additional file 1: Table S1).

\section{Discussion}

This is the first study to evaluate opioid switch directly from low dose of oral oxycodone to fentanyl matrix patch in patients with malignancy-related pain.

Another Japanese study also investigated opioid switch to $12.5 \mu \mathrm{g} / \mathrm{h}$ of fentanyl matrix patch from various opioids. This study was different from ours in the following three points; 1) including various kinds of prior opioid; oral oxycodone $<30 \mathrm{mg} /$ day $(69.4 \%)$, intravenous fentanyl injection $<0.3 \mathrm{mg} /$ day $(1.2 \%)$ and oral, transanal or intravenous morphine $(29.4 \%), 2)$ recruiting patients with various types of primary cancers, including $34 \%$ of respiratory cancer, 3) assessing patients' global pain assessment only at day 10, during third patch application, or the day of protocol withdrawal [20]. We focused on switch only from oral oxycodone $\leq 20 \mathrm{mg} /$ day, recruited only patients with thoracic malignancy, and compared patients' global assessments among 3 measurement days.

The most important finding of our study was that patients' satisfaction was improved by opioid switch from oral oxycodone to fentanyl patch. More than $80 \%$ of patients did not feel dissatisfied in the patients' global assessment scores, which met the primary endpoint. Contrast to no difference in ESS score, sleepiness was significantly improved by opioid switch. Moreover, favorable changes were conceivably noted in constipation, though the improvement in constipation did not reach statistical significance. In the four-point categorical rating scale of sleepiness (scales $0-3$ ), the number of patients with scale 0 increased from 6 on day 1 up to 19 on day 15, while that with scale 1 decreased from 29 down to 20. In the assessment of constipation, all 5 patients with scale 2 or 3 on day 1 improved to scale 0 or 1 on day 15 , while one patient with scale 0 on day 1 deteriorated into scale 2 on day 15 (Additional file 1: Table $\mathrm{S} 1$ ). These changes were similar to those in the study by Miyazaki et al., in which the rate of 'very satisfied' and 'satisfied' increased over time after opioid switch to fentanyl patch [20].

The second important finding was that conversion rate from oral oxycodone to fentanyl patch was not uniform. In our study, various doses of oral oxycodone from 10 to $20 \mathrm{mg} /$ day were switched uniformly to $12.5 \mu \mathrm{g} / \mathrm{h}$ of fentanyl patch. Not a few patients felt pain of NRS $\geq 4$ and needed increase of fentanyl patch thereafter. The equivalent dose of fentanyl patch to oral oxycodone was not definite in our study, though an initial conversion from $10-20 \mathrm{mg} /$ day of oral oxycodone to $12.5 \mu \mathrm{g} / \mathrm{h}$ of fentanyl patch seems safe and reasonable. Thus, we have to pay careful attention to switch from oral oxycodone to

Table 3 Dose of oral oxycodone and transdermal fentanyl matrix patch at day 0,8 and $15(\mathrm{~N}=49)$

\begin{tabular}{|c|c|c|c|c|c|c|}
\hline Opioids & \multicolumn{2}{|c|}{ Day 1} & Fentanyl patch & & Fenta & \\
\hline \multicolumn{7}{|l|}{ Dose } \\
\hline Mean \pm SD & \multicolumn{2}{|c|}{$14.7 \pm 4.1 \mathrm{mg} /$ day } & \multicolumn{2}{|c|}{$13.7 \pm 4.8 \mu \mathrm{g} / \mathrm{h}$} & \multicolumn{2}{|c|}{$15.5 \pm 6.0 \mu \mathrm{g} / \mathrm{h}$} \\
\hline \multirow[t]{4}{*}{ Patients' distribution (N) } & 10 mg/day & 18 & $12.5 \mu \mathrm{g} / \mathrm{h}$ & 44 & $12.5 \mu \mathrm{g} / \mathrm{h}$ & 38 \\
\hline & 15 mg/day & 16 & $18.8 \mu \mathrm{g} / \mathrm{h}^{*}$ & 1 & $18.8 \mu \mathrm{g} / \mathrm{h}^{*}$ & 1 \\
\hline & 20 mg/day & 15 & $25.0 \mu \mathrm{g} / \mathrm{h}$ & 3 & $25.0 \mu \mathrm{g} / \mathrm{h}$ & 9 \\
\hline & & & $37.5 \mu \mathrm{g} / \mathrm{h}$ & 1 & $37.5 \mu \mathrm{g} / \mathrm{h}$ & 1 \\
\hline
\end{tabular}

All patients were switched from oral oxycodone to $12.5 \mu \mathrm{g} / \mathrm{h}$ of fentanyl matrix patch at day 1 . 
Table 4 Change of numeric rating scale (NRS) of pain intensity and use of rescue immediate-release oxycodone

\begin{tabular}{lccc}
\hline & Day $\mathbf{1}$ & Day $\mathbf{8}$ & Day 15 $^{\mathbf{1 5}}$ \\
\hline NRS pain intensity $(\mathrm{N}=49)$ & & & 0.15 \\
Mean \pm SD & $2.2 \pm 1.4$ & $2.1 \pm 1.5$ & $1.9 \pm 1.4$ \\
Median (range) & $2(0-6)$ & $2(0-7)$ & $2(0-6)$ \\
NRS $0-3 / \geq 4$ & $43 / 6$ & $41 / 8$ & $43 / 6$ \\
Immediate-release oxycodone (mg / day) $(\mathrm{N}=48)^{\mathrm{b}}$ & & & $2.2 \pm 2.7$ \\
Mean \pm SD & $1.9 \pm 2.2$ & $2.7 \pm 3.5$ & $1.75(0-10)$ \\
Median (range) & $2.5(0-10)$ & $2.5(0-15)$ & 0.36 \\
\hline
\end{tabular}

SD; standard deviation.

${ }^{\mathrm{a}}$ Friedman test.

${ }^{b}$ One patient was excluded from analysis of rescue use because of missing data throughout all the three observation points. The remaining 48 patients completed data collection.

fentanyl patch for fear of insufficient pain control or overdose.

Our study included some limitations. First, our study was not blinded. A bias derived from different formulations was possible. Second, we used an unvalidated tool to assess constipation, thereby this adverse event might be either underestimated or overestimated. Third, more than half patients concomitantly received other cancer treatment such as chemotherapy or radiotherapy. Because these concomitant treatments possibly influenced cancer pain, the true analgesic power of fentanyl patch was uncertain in those patients. Considering the poor prognosis of advanced lung cancer, we could not forbid any other cancer treatments during the study period. Fourth, the day 1 at opioid switch might not be appropriate as a baseline assessment for comparison with day 8 and 15. In addition, we should have standardized the timing of diary record. Although all patients had reported pain of NRS $\leq 3$ until the previous day of opioid switch, six patients suffered from pain of NRS level $\geq 4$ at the day of opioid switch (on day1). Five of these 6 patients converted opioids on dayl in our hospitals, and recorded their diaries on day 1 before or at the same time as the first application of fentanyl patch. Because

Table 5 Adverse events

\begin{tabular}{|c|c|c|c|c|c|}
\hline & $\mathbf{N}$ & Day 1 & Day 8 & Day 15 & $p$-value ${ }^{a}$ \\
\hline Sleepiness & 45 & & & & 0.004 \\
\hline Mean \pm SD & & $1.2 \pm 0.7$ & $0.9 \pm 0.6$ & $0.73 \pm 0.8$ & \\
\hline Median (range) & & $1(0-3)$ & $1(0-2)$ & $1(0-3)$ & \\
\hline vs. day $1^{\mathrm{b}}$ & & & n.s. & $<0.05$ & \\
\hline Nausea & 49 & & & & 0.87 \\
\hline Mean \pm SD & & $0.4 \pm 0.8$ & $0.4 \pm 0.7$ & $0.3 \pm 0.6$ & \\
\hline Median (range) & & $0(0-3)$ & $0(0-3)$ & $0(0-2)$ & \\
\hline Vomit & 49 & & & & 0.66 \\
\hline Mean \pm SD & & $0.1 \pm 0.6$ & $0.2 \pm 0.6$ & $0.1 \pm 0.5$ & \\
\hline Median (range) & & $0(0-3)$ & $0(0-3)$ & $0(0-2)$ & \\
\hline Constipation & 48 & & & & 0.08 \\
\hline Mean \pm SD & & $0.5 \pm 0.7$ & $0.3 \pm 0.5$ & $0.3 \pm 0.5$ & \\
\hline median (range) & & $0(0-3)$ & $0(0-2)$ & $0(0-2)$ & \\
\hline Defecation number (/ day) & 49 & & & & 0.85 \\
\hline Mean \pm SD & & $1.1 \pm 1.0$ & $1.0 \pm 0.8$ & $1.0 \pm 0.7$ & \\
\hline Median (range) & & $1(0-4)$ & $1(0-4)$ & $1(0-4)$ & \\
\hline Epworth Sleep Scale & 49 & & & & 0.96 \\
\hline Mean \pm SD & & $6.3 \pm 4.0$ & $6.1 \pm 4.2$ & $6.0 \pm 4.2$ & \\
\hline Median (range) & & $6(0-16)$ & $5(0-18)$ & $5(0-19)$ & \\
\hline
\end{tabular}

SD; standard deviation, n.s.; not significant $(p>0.05)$.

${ }^{\text {a }}$ Friedman test.

${ }^{\mathrm{b}}$ Post-hoc nonparametric multiple comparison analysis was performed using Steel method after significant difference in assessment scores across multiple points was detected by Freidman test $(p=0.01)$. 
we did not know when the remaining one outpatient had written diaries on day 1 at home, this patient might have severer pain than usual by the confusion from oral oxycodone to fentanyl patch. Fifth, we did not grasp the precise number of ineligible patients who dropped out during oxycodone treatment due to uncontrollable pain by $20 \mathrm{mg} /$ day of oral oxycodone. Thus, we failed to clarify the proportion of eligible patients for this opioid switch maneuver in all patients with thoracic malignancy-related pain requiring strong opioid. Based on the study limitations described above, we are considering a cross-over trial comparing in pain control and adverse severity between fentanyl patch and oral opioid for cancer-related pain, instead of a randomized blinded controlled trial. Our study group is still too small to conduct such a high level of trial.

\section{Conclusion}

Transdermal fentanyl matrix patch is an alternative analgesic option for a stable cancer pain in patients with thoracic malignancies.

\section{Additional file}

Additional file 1: Table S1. The patients' distribution of adverse events.

\section{Competing interest}

The authors declare that they have no competing interests.

\section{Authors' contribution}

TK designed the study. SM and TK analyzed the data and wrote the manuscript. All authors accrued and managed patients, collected data, read and approve this manuscript, and agree to its submission.

\section{Acknowledgements}

We thank all the investigators who recruited patients in the trial; Isao Tachibana, Hiroshi Kida, Ryo Takahashi, Toshiyuki Minami, Kotaro Miyake, Masayoshi Higashiguchi (Osaka University Graduate School of Medicine), Masanari Hamaguchi, Yoshiko Takeuchi (Osaka Police Hospital).

\section{Author details}

'Department of Respiratory Medicine, Osaka Police Hospital, 10-31 Kitayama-cho, Tennoji-ku, Osaka 543-0035, Japan. ²Department of Respiratory Medicine, Allergy and Rheumatic Diseases, Osaka University Graduate School of Medicine, 2-2 Yamada-oka, Suita, Osaka 565-0871, Japan.

Received: 23 April 2014 Accepted: 2 October 2014

Published: 8 October 2014

\section{References}

1. Jost L, Roila F, Group EGW: Management of cancer pain: ESMO Clinical Practice Guidelines. Ann Oncol 2010, 21(Suppl 5):v257-260.

2. Kroenke K, Theobald D, Wu J, Loza JK, Carpenter JS, Tu W: The association of depression and pain with health-related quality of life, disability, and health care use in cancer patients. J Pain Symptom Manage 2010, 40(3):327-341.

3. Caraceni A, Hanks G, Kaasa S, Bennett MI, Brunelli C, Cherny N, Dale O, De Conno F, Fallon M, Hanna M, Haugen DF, Juhl G, King S, Klepstad P, Laugsand EA, Maltoni M, Mercadante S, Nabal M, Pigni A, Radbruch L, Reid C, Sjogren P, Stone PC, Tassinari D, Zeppetella G: Use of opioid analgesics in the treatment of cancer pain: evidence-based recommendations from the EAPC. Lancet Oncol 2012, 13(2):e58-68.
4. King SJ, Reid C, Forbes K, Hanks G: A systematic review of oxycodone in the management of cancer pain. Palliat Med 2011, 25(5):454-470.

5. Reid CM, Martin RM, Sterne JA, Davies AN, Hanks GW: Oxycodone for cancer-related pain: meta-analysis of randomized controlled trials. Arch Intern Med 2006, 166(8):837-843.

6. Riley J, Eisenberg E, Muller-Schwefe G, Drewes AM, Arendt-Nielsen L: Oxycodone: a review of its use in the management of pain. Curr Med Res Opin 2008, 24(1):175-192.

7. Mercadante S, Porzio G, Ferrera P, Aielli F, Adile C, Ficorella C: Low doses of transdermal fentanyl in opioid-naive patients with cancer pain. Curr Med Res Opin 2010, 26(12):2765-2768.

8. Ahmedzai S, Brooks D: Transdermal fentanyl versus sustained-release oral morphine in cancer pain: preference, efficacy, and quality of life. The TTS-Fentanyl Comparative Trial Group. J Pain Symptom Manage 1997, 13(5):254-261

9. Allan L, Hays H, Jensen NH, de Waroux BL, Bolt M, Donald R, Kalso E: Randomised crossover trial of transdermal fentanyl and sustained release oral morphine for treating chronic non-cancer pain. BMJ 2001 322(7295):1154-1158.

10. Donner B, Zenz M, Tryba M, Strumpf M: Direct conversion from oral morphine to transdermal fentanyl: a multicenter study in patients with cancer pain. Pain 1996, 64(3):527-534

11. Kress HG, Von der Laage $D$, Hoerauf $K H$, Nolte $T$, Heiskanen $T$, Petersen $R$, Lundorff L, Sabatowski R, Krenn H, Rosland JH, Saedder EA, Jensen NH: A randomized, open, parallel group, multicenter trial to investigate analgesic efficacy and safety of a new transdermal fentanyl patch compared to standard opioid treatment in cancer pain. J Pain Symptom Manage 2008, 36(3):268-279.

12. Radbruch L, Sabatowski R, Loick G, Kulbe C, Kasper M, Grond S, Lehmann KA: Constipation and the use of laxatives: a comparison between transdermal fentanyl and oral morphine. Palliat Med 2000, 14(2):111-119.

13. Hadley G, Derry S, Moore RA, Wiffen PJ: Transdermal fentanyl for cancer pain. Cochrane Database Syst Rev 2013, 10:CD010270.

14. Tassinari D, Sartori S, Tamburini E, Scarpi E, Tombesi P, Santelmo C, Maltoni M: Transdermal fentanyl as a front-line approach to moderate-severe pain: a meta-analysis of randomized clinical trials. J Palliat Care 2009, 25(3):172-180.

15. Tassinari D, Drudi F, Rosati M, Maltoni M: Transdermal opioids as front line treatment of moderate to severe cancer pain: a systemic review. Palliat Med 2011, 25(5):478-487.

16. Wirz S, Wittmann M, Schenk M, Schroeck A, Schaefer N, Mueller M, Standop J, Kloecker N, Nadstawek J: Gastrointestinal symptoms under opioid therapy: a prospective comparison of oral sustained-release hydromorphone, transdermal fentanyl, and transdermal buprenorphine. Eur J Pain 2009 13(7):737-743.

17. Mercadante $S$ : Opioid rotation for cancer pain: rationale and clinical aspects. Cancer 1999, 86(9):1856-1866.

18. Morita T, Takigawa C, Onishi H, Tajima T, Tani K, Matsubara T, Miyoshi I, Ikenaga M, Akechi T, Uchitomi Y, Japan Pain, Rehabilitation Palliative Medicine Psycho-Oncology Study, Group: Opioid rotation from morphine to fentanyl in delirious cancer patients: an open-label trial. J Pain Symptom Manage 2005, 30(1):96-103.

19. Takakuwa O, Oguri T, Maeno K, Yokoyama M, Hijikata H, Uemura T, Ozasa H, Ohkubo H, Miyazaki M, Niimi A: Analgesic effect of switching from oral opioids to a once-a-day fentanyl citrate transdermal patch in patients with lung cancer. Am J Hosp Palliat Care 2013, 30(7):726-729.

20. Miyazaki T, Hanaoka K, Namiki A, Ogawa S, Kitajima T, Hosokawa T, Ishida T, Nogami S, Mashimo S: Efficacy, safety and pharmacokinetic study of a novel fentanyl-containing matrix transdermal patch system in Japanese patients with cancer pain. Clin Drug Investig 2008, 28(5):313-325.

doi:10.1186/1472-684X-13-46

Cite this article as: Minami et al:: Opioid switch from low dose of oral oxycodone to transdermal fentanyl matrix patch for patients with stable thoracic malignancy-related pain. BMC Palliative Care 2014 13:46. 